\title{
Four spaces of network learning models
}

\author{
Tak-Wai Chan ${ }^{\mathrm{a}, *}$, Chih-Wei Hue ${ }^{\mathrm{b}}$, Chih-Yueh Chou ${ }^{\mathrm{a}}$, Ovid J.L. Tzeng \\ ${ }^{a}$ Department of Computer Science and Information Engineering, National Central University, Chungli, Taiwan \\ ${ }^{\mathrm{b}}$ Department of Psychology, National Taiwan University, Taipei, Taiwan \\ ${ }^{\mathrm{c} C e n t e r}$ of General Education, National Yang-Ming University, Taipei, Taiwan
}

Received 7 August 2000; accepted 15 April 2001

\begin{abstract}
The development of information and communication technology changes how, what, who, when, where and why we learn. Unfortunately, little is known of the exact impact that these changes will bring to education. However, we are certain that many new learning and teaching styles which are called learning models in the paper will emerge to cope with the changes in the near future. The present paper describes four spaces of learning models, namely, the future-classroom, the community-based, the structuralknowledge, and the complex-problem learning models, which are specifically designed to integrate the Internet into education. ${ }^{1}$ With the four spaces of learning models, the present paper may serve two functions. First, it offers a way to integrate an array of different communication technologies (e.g. handheld computer, wireless communication and the Internet) and learning theories into an integrated schema. Secondly, the paper offers a direction concerning how and what to look for in education with the Internet integrated in. (C) 2001 Elsevier Science Ltd. All rights reserved.
\end{abstract}

Keywords: Distance education; Distributed learning environments; Cooperative/collaborative learning; Learning communities; Intelligent tutoring systems

\section{What is learning technology?}

Despite that schooling has been practiced in human societies for thousands of years and education has been the main means to transmitting culture from generation to generation, education or learning benefits little from human invented artifacts, perhaps except the printing press which is a device for printing from inked plates invented by the Chinese in the second century AD. In

* Corresponding author. Tel.: + 886-3-4227151-7821; fax: + 886-3-427.

E-mail addresses: chan@src.ncu.edu.tw (T.-W. Chan), hue@ccms.ntu.edu.tw (C.-W. Hue), otzeng@ym.edu.tw (O.J.L. Tzeng), yueh@src.ncu.edu.tw (C.Y. Chou).

1 The concepts and ideas underlying this paper are the results of numerous and prolonged discussions of a group of researchers in Taiwan under the support of a grant from the Ministry of Education of Taiwan, the Republic of China. 
the past 5000 years of human history, a few human inventions could be identified, which have significant influence in education. The first is the re-invention of the printing press about 500 years ago by Gutenberg in Germany. This invention led to the rapid increase of printed works and facilitating knowledge dissemination in the West. The second and the third are the computer and the Internet, which were invented about 50 and 5 years ago, respectively. The invention of the computer and Internet not only increases the speed of knowledge generation, but also changes how knowledge transmits from one person to another. It is hard to predict how technology will evolve in the next 5 years, and how the newly invented technologies affect the way our children learn in the next 50 years (Fig. 1). When changes happen so fast, research on learning technology should focus on where the changes are leading to, but this has never been easy.

"Learning technology" denotes the research on and implementation of various kinds of technologies to support learning. However, in the present paper, we are focusing the discussion on the impact of the information and communication technologies on education, concerning how, what, who, when, where and why to learn. However, learning technology is still not a common term due to the fact that in the past, the study of "applying" technology for learning had been much more than "developing" new technology for learning. Furthermore, despite the advance of computing technology, such as artificial intelligence and multimedia, the study did not produce enough noteworthy theories and results to uphold long lasting research. The swift evolution and disparity of technology are the major causes. Development of prototype after prototype of learning aids was what most researchers did, while the others stood by and speculated. These prototypes, unfortunately, became obsolete as soon as they were finished. Dissemination of research results was further limited by not having a real learning technology industry because of the immature market.

However, the slow progress of learning technology will change. Every family, every classroom in a school, and even anyone on the street will soon be able to afford a computer in some form, and learning is one of its applications. The present paper argues that a large number of network learning models will emerge in the near future. Being alternatives of the learning models we are used to, these new models will inherently change the way we learn and even our impression of schools. We are also arguing that much research is needed to identify, experiment, and materialize the effectiveness of these new learning models. The present paper reports the efforts we are making in Taiwan on that direction.

\section{Spaces of learning models}

In 1992, Chan, Chung, Ho, and Lin, (1992) developed a simple dedicated network learning environment, called Distributed West, in which two students or two groups of students interact

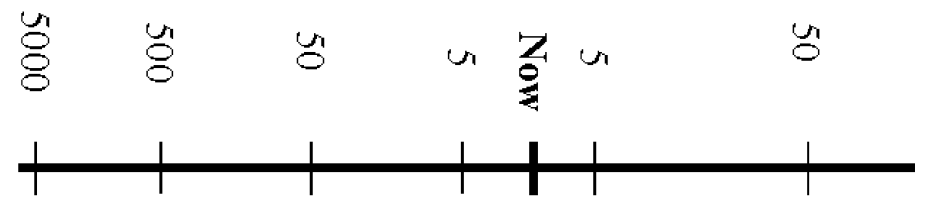

Fig. 1. Timeline of development. 
synchronously via two connected computers, using RS232 for connection. Considering the relationships and the types of interactions among the students, and the roles and the numbers of artificial agents simulated in the computers, Chan et al. enumerated 768 network learning models.

Barnard and Sandberg (1993) presented another perspective of the new computer-connected learning environment. In their "learner at the center" proposal, Barnard and Sandberg argued that the computer network could bring a variety of educational resources to a learner. This view is particularly useful nowadays, where the Internet can be accessed from schools, public libraries, and learners' houses. It is predictable that through the Internet, a supportive learning network can be easily created for a learner. The learner can access electronic multimedia books collected in digital libraries. $\mathrm{S} /$ he can also visit virtual museums, and during the visit review the questions asked by other visitors. The learner and, perhaps with permission, the teachers can also review her/his learning portfolios, to find out how her/his efforts were allocated in the various activities engaged in the Internet. As a communication medium, the Internet enables the learner to connect with her/his teachers and fellow learners, and volunteer tutors, etc. In addition, the learner is empowered by expensive equipment which be remote controlled through the learner's home computer, cognitive tools, and computer simulated educational agents (such as tutors, learning companions, etc.; Fig. 2).

The "connectivity" of the Internet plays the key role in Barnard and Sandberg's (1993) proposal. The Internet connects all the potential resources (learning materials, learning companions, resource personals, and cognitive tools, etc.) scattered all over the world. Numerous models of network learning, that is, protocols of actions taken by participants on the network, can be designed to exploit this unlimited learning environment. These models, not only lead to learning, but also change the ways we learn.

The network consisted of Intranet, Internet, and all types of wireless communication networks brings down the constraints of space and time, because a learner can interact with other learners around the clock and at a very short time, even though they are at different locations. Thus, the network affords new learning activities, in addition to the traditional ones where the learners come to same location at the time (4th quadrant in Fig. 3), such as the network chat-room

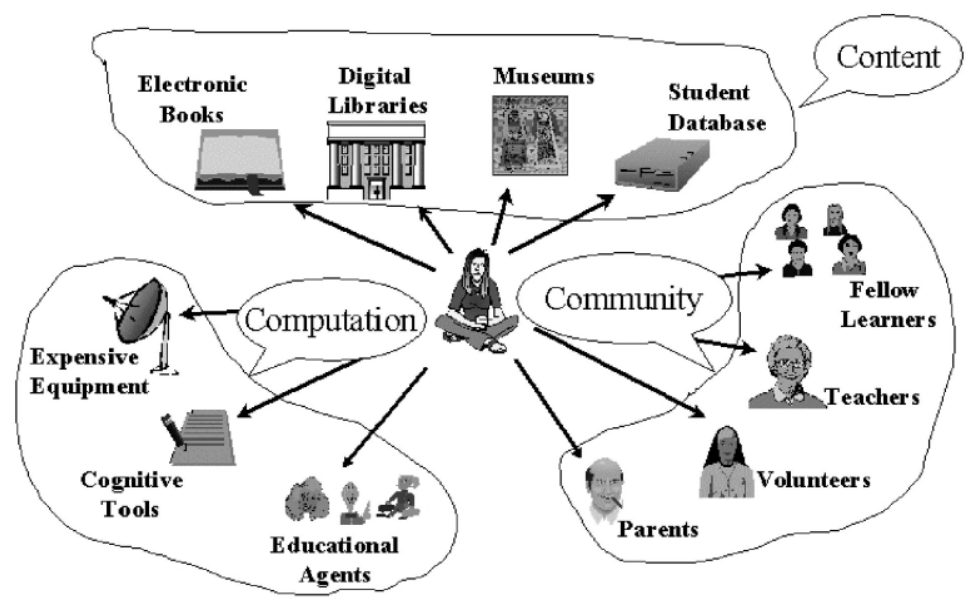

Fig. 2. Learner at the center. 


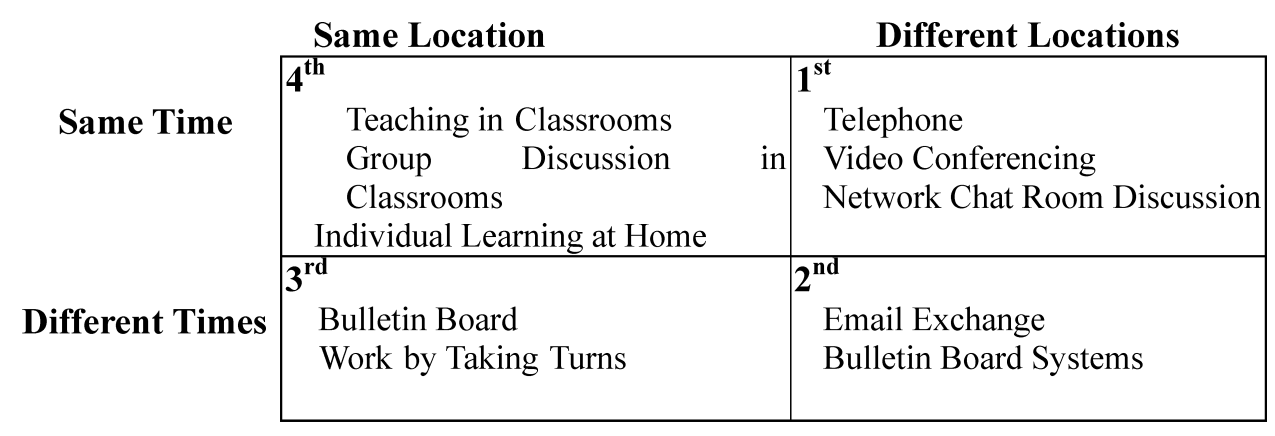

Fig. 3. Classification of learning activities.

discussion which requires only the learners from different locations log on the network at the same time (1st quadrant), and the bulletin board systems which allows the learners from different locations to post and read information around the clock (2nd quadrant). Although in theory, we can ask learners to go to a specific location at different time, learning activities of this type are not practical. As can be seen in Fig. 3, most learning models, which are in traditional classroom settings or at home, lie in the 4th quadrant. However, numerous network learning models lie in the 1st and 2nd quadrants will emerge in the future. It is also possible that a learning task involves activities from the 1st, 2 nd, and 4th quadrants.

It is tempting to find out which network learning model(s) fit the best of the network, where there is ubiquitous accessibility of unlimited learning resource. But, before we can do that, we have to identify the possible spaces of network learning models. The rest of this paper will describe the scope of these spaces, which, we hope, will provide a profound grasp of the future changes in education.

\subsection{Network learning models}

Despite being a valuable conceptual view, "learner at the center" cannot lead to any description or concrete design of learning models. Educational problems, in general, are extremely complex. A way of handling a complex problem is through decomposition, such as breaking down the problem into sub-problems, or doing what we are doing here, by identifying important issues of the problem space, which have to be handled. There are a number of important educational issues in which information technology can play a critical role. These issues, which are actually educational reform movements, have been already taking shape and will soon affect our daily life and the society in general. We have identified four spaces of network learning models, and use these models as a means of coping with these issues.

This issue-based approach of decomposing educational problems into learning models is a balance of finding problem solutions and posing theories of network learning. In other words, this approach enables a theory of network learning to evolve and be enriched, and hence drive the development of technology support for learning. This is also a way of ensuring impacts of the outcomes both in research and practice. There are three issues of which the four spaces of learning models are meant to cope with. 
The first issue is the change in physical learning environment, in particular, the change of classroom settings and activities by wireless and mobile computing. This will change the ecology in a classroom, especially the role of a teacher. "Connected" classrooms, through computers, will change the organizational structure of schools, and the definition of a class. What drives this change will be a space of network learning models referred to as the future classroom learning (Fig. 4).

The second issue is the change of the purposes of education. That is, what and why to learn in the new century will be different from that of the past. The purpose of education should be more than teaching students a body of knowledge, which is emphasized in current education. In addition, education should allow students to acquire a healthy self-concept, skills of emotional management, and the ability to search and integrate information to solve problems (Whitaker, 1995). In other words, the purpose of education is to make a student (or citizen) a good decision maker, a creative and self-reliant problem solver, who will be able to adapt well in the twenty-first century. Furthermore, facing the inevitable global competition, every country is exposed to tremendous pressure to reform education in such a way that all the citizens have opportunities to learn new or update their old knowledge throughout their life. Thus, not only do the purposes of learning change, but also the content of education (or the curriculum) and the constituents of students change too. In other words, there will be a paradigm shift in learning and education. In responding to these changes, we propose two spaces of network learning models, namely, structural knowledge learning and complex problem learning.

The final issue is the emerging of network societies. Just as they are in the "real" world, the Internet users formed groups, have their own languages, customs and cultures (Wallace, 1999).

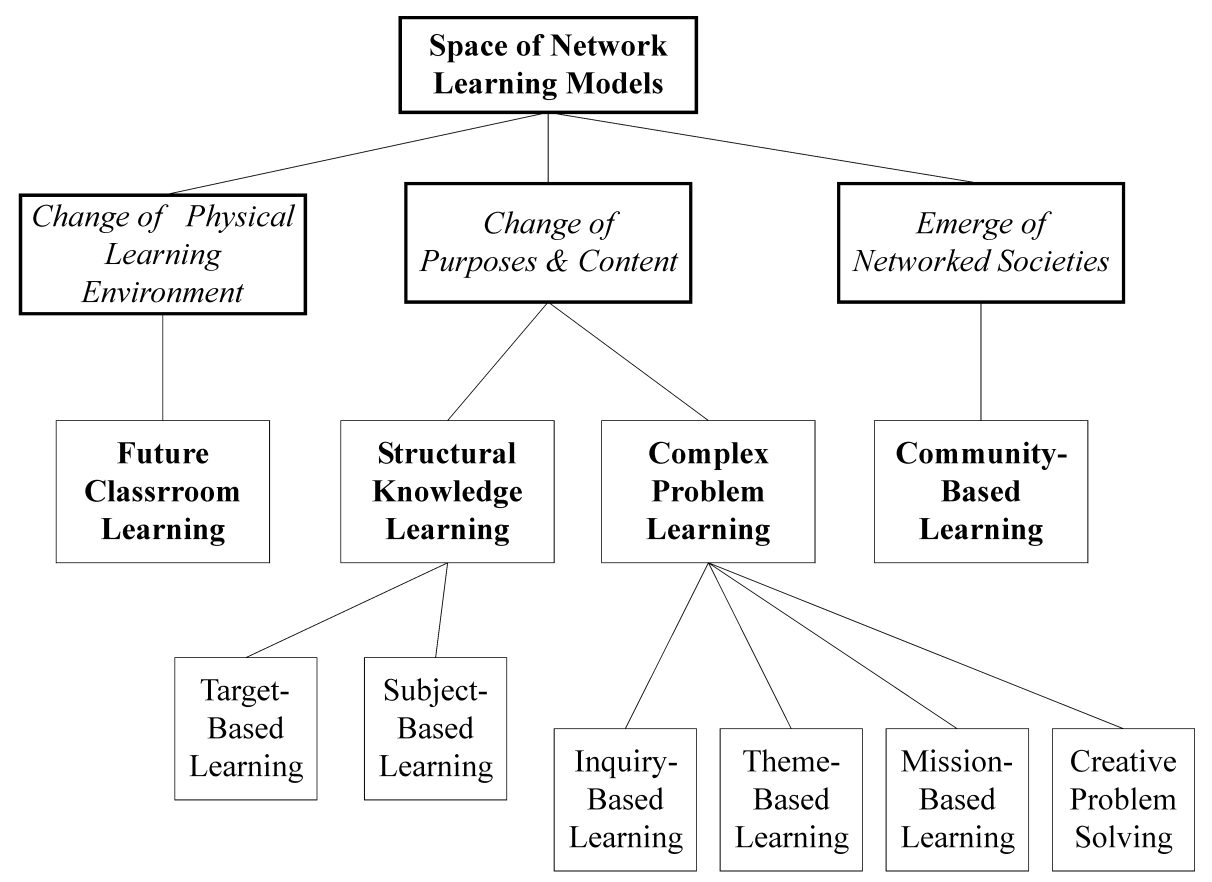

Fig. 4. Hierarchy of network learning model spaces. 
As the Internet (and other telecommunication networks) gradually intermixes into our everyday life (work, social activities, learning, entertainment, etc.), it is essential to nurture network users at an early age to become behaved "network citizens". To cope with this, we propose to build a network society, and then embed learning activities, called community-based learning, in it.

\subsection{Future classroom learning}

The first issue is the change of the physical learning environments caused by the use of wireless and mobile computing technology in classrooms. The appearance and function of a computer will be very different in 10 years from what we see today, and be designed according specific purposes. For example, a student's schoolbag can be a hand-held computer with wireless connections to school computers, where the student can download electronic books, assignments, and examinations, etc. Used together with electronic whiteboard, these schoolbag computers will transform a static classroom into a highly interactive learning environment.

By connecting classrooms through computers, the teachers of the connected classrooms can collaborate to design better learning activities, and the students can form teams, across different classrooms, to participate in the activities. The classrooms connected may be within the same or different schools, or even from schools of different countries. It is also possible, for example, a student while visiting a museum discovers something interesting, and then, with a handheld computer, the student is able to find other students in the museum with similar interests. The students can form an ad hoc class to discuss their common interest. This is a kind of application of ICQ, user modeling, and mobile computing.

In the remote laboratory, students can control remote expensive equipment, for example, an astronomy telescope. With technology, the building of a classroom no longer confines the students' interactions to other students of the same room, and the learning materials to those stored in the building. Learning is omnipresent and can happen within or outside of a traditional classroom, and thus extends the concept of "classroom".

\subsection{Change of purposes of education}

The second issue is the recent movements of educational reforms in many Asian countries and areas, for instance in Taiwan (Ministry of Education, 1998), Hong Kong (Education and Manpower Bureau, 1998, 2000), and Singapore (Ministry of Education, 1997), where knowledge acquisition is emphasized in education. However, the reform of education in these areas emphasizes learning beyond learning. In addition to the basic training of Reading, wRiting, and aRithmetic, the development of reasoning (the fourth $\mathrm{R}$ ) and problem solving abilities and social and self-presentation skills are emphasized in schools as well. The purposes of education are expanded, or will expand, from IQ (Intelligence Quotient) to EQ (Emotional Intelligence Quotient), CQ (Creativity Quotient), AQ (Adversity Quotient), and SQ (Sociality Quotient; Chan, 1999; Fig. 5). AQ quotient is defined as the ability to prevail and succeed in the face of adversity. With such ability, one may turn obstacles into opportunities (Stoltz \& Pulatie, 1997). Although most of these "Qs", except IQ, have not been formally defined, we mean to use them to emphasize what students need in the twenty-first century. To reflect on this fundamental change in education, two spaces (structural knowledge learning and complex problem learning) of network learning models are proposed. 


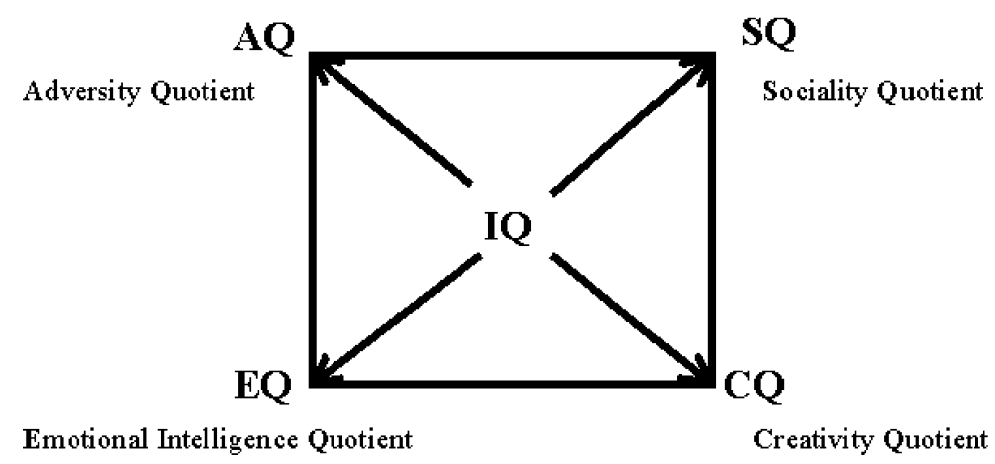

Fig. 5. Expanding goals of education.

No matter what change in the content of learning, proficiency of some basic knowledge or skills, such as pronunciation of words and arithmetic, remains the foundation for further learning. Structural knowledge learning will follow the traditional method of content design. That is, it relies on task analysis to decompose the to-be-learnt materials into smaller units and to arrange these units into a hierarchical structure. Arrangement of teaching and learning activities are based on this structure. Complex problem learning, on the other hand, can be regarded as the response to the call for changing the purposes of education and developing students' abilities such as creativity, critical thinking, learning how to learn, teamwork, social responsibility, etc. The next two sections discuss these two spaces in further details.

\subsection{Structural knowledge learning}

Structural knowledge learning is further divided into target-based learning and subject-based learning. A target in the target-based learning is referred to a small unit of learning. Target-based learning assumes that a knowledge unit, if needed, can be further decomposed into smaller units until each of them is teachable, and can be drilled. The basic idea of target-based learning follows Gagne's theory on condition of learning (Gagne, 1985). He suggested, through the process of task analysis, to organize a complex learning task into a hierarchy simple learning tasks. The purpose of the hierarchy is to identify prerequisites that should be completed to facilitate learning at another level. Learning hierarchies provides a basis for the sequencing of instruction. This approach is important in learning basic skills such as reading, writing and arithmetic.

Target-based learning stresses the customization of the software, that is, the response of the system will be tailored to the user's need. Although structural knowledge learning is similar to the traditional computer assisted instruction (CAI) or the intelligent CAI software in terms of content arrangement, the designs of learning tasks are different. That is, most of the traditional CAI or ICAI systems follow the principles of behaviorism to design the learning tasks; recent learning theories, such as scaffolding, are incorporated in the structural knowledge learning.

Below is an example giving a flavor of how target-based learning can be applied by exploiting computational scaffolding and social scaffolding. The target is learning a linear equation. By clicking buttons of the panel on the right hand, the student can subtract the equation on both sides by " $3 x$ ", and then after hitting the "simplify' button, the equation has a " $-x$ " on the left- 
hand-side of the equation. For those who have trouble with " $-x$ ", they can get around the difficulty by multiplying the equation on both sides by "4" and then dividing both sides by " -4 ", and finally get the answer (Fig. 6).

Several points should be noted about the system. First, it provides computational scaffolding. That is, the system supports the student's work on problems by solving part of a problem while the student finishes the rest. In this example, the system did the computation while the student designed the problem-solving plan. Thus, the system easies the computational burden, and should allow the student to attend to the structural features of the problem. In addition, computational scaffolding can be designed in a such way that critical hints will be provided when a student is at a deadlock while solving a problem. The hinds provided by the system shed light on how the problem should be represented, and the student should try to plan a potential solution based on the representation. With computational scaffolding, the student hardly makes mistakes. Although the answer or the solution path may not be optimal, the successful experiences should boost students' interests and motivation in learning.

Secondly, fellow learners on the network are valuable and huge human resources that could never be exploited in traditional school settings. In this example, it is easy to imagine that two students on the network can solve the problem collaboratively. For example, each student may take turns to work on a problem, and exchange ideas in the process of solving the problem. This type of support is termed as social scaffolding. Dyad interactions on the network are a basic form of network learning. Depending on the design of the learning activities, the dyad relationship can be collaborators, opponents, or tutor-tutee relationship, that is, one plays the role of a peer tutor who tutors the other (Fig. 7).

A student will not learn multiplication if not competent with addition, and will not learn division without mastering subtraction. Thus, target-based learning demands many complementary materials or software to learn a single target. For example, if a student cannot understand the concept of subtraction, there are multiple ways of introducing the concept from different perspectives. Therefore, scaling up target-based learning by integrating software of different targets

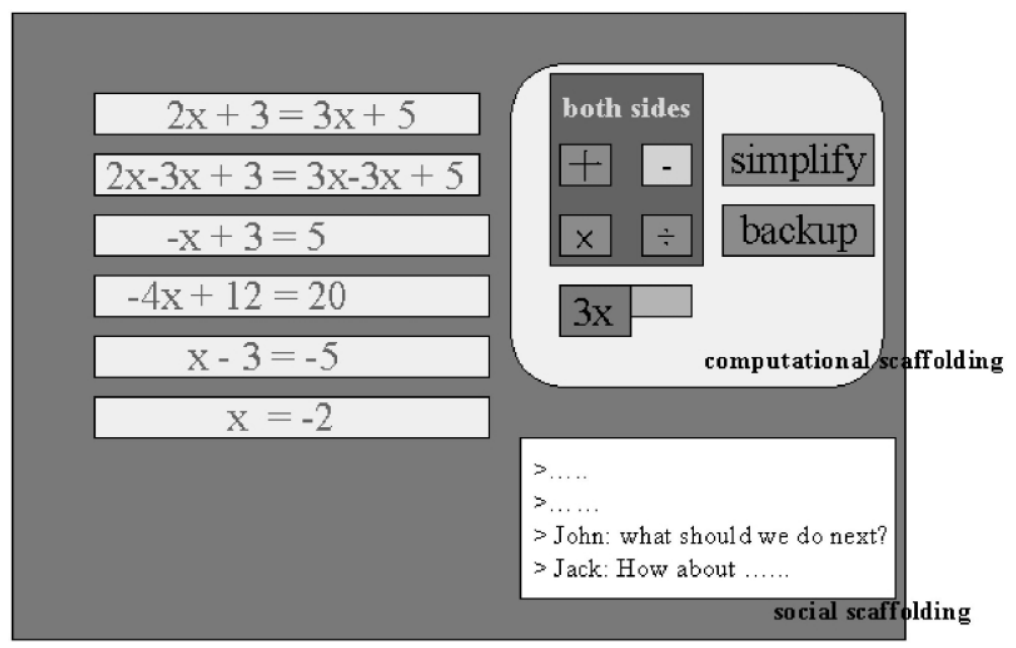

Fig. 6. Example of target-based learning with scaffolding. 


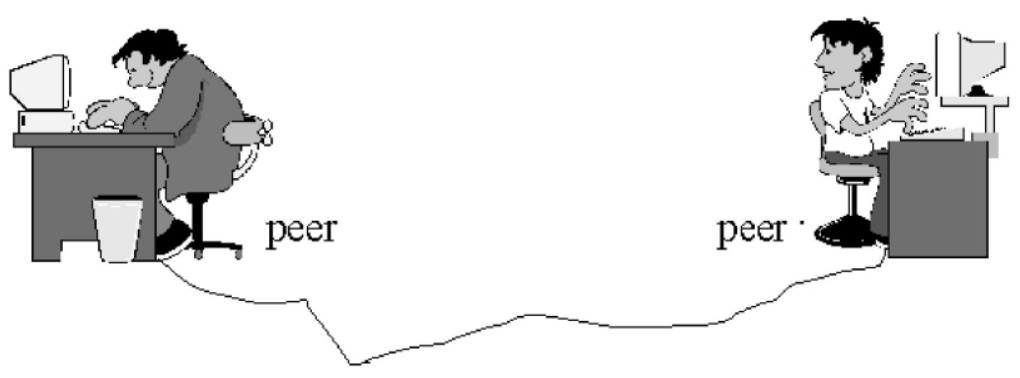

Fig. 7. Dyad learning on network.

to form a complete curriculum will be a challenge in the future. However, past experience tells that software design even for just a single target is rather labor intensive. Finally, scaffolding is usually coupled with fading, that is, when the student gradually learn the task, external helps should be gradually reduced. Therefore, as Brown (1988) argued, scaffolding is a safe form of learning.

Subject is a package of learning units to form a course. A subject in subject-based learning can be regarded as an aggregate of learning targets. Thus, main concern of the subject-based learning is the management of a course such as delivering and submission of assignments through the network, maintaining grades, tracing of students' behaviors and performance on the network, providing recommendations for the teacher, coordinating student activities as well as supporting inter-class collaborative teaching, etc. These essentially are the functions provided by many Webbased asynchronous learning systems commonly seen nowadays.

\subsection{Complex problem learning}

Complex problem learning, generally called project-based learning, ${ }^{2}$ intends to promote students to accomplish a task in teams, and is designed to encourage students to integrate and to use the information extracted from the network in a creative way to solve problems. Complex problem learning can be further decomposed into four spaces to address different perspectives. In inquirybased learning, a student is like a scientist, and will do what a scientist does when conducting a research. That is, in an inquiry-based learning activity, the student will perform the following activities: formulate authentic and meaningful questions or ideas, plan tasks, collaborate with others, gather resources and information, predict outcomes, debate and evaluate the relevance of information, test, revise and formulate questions or ideas, and report findings (Bell, et. al., 1995; Hoffman, et. al., 1997; Krajcik, 2000). This genre of learning has recently drawn a lot of attention in North America. In the theme-based-learning, a student learns a theme from different perspectives. For example, one can discuss "water" from scientific, social and environmental development, or historical points of view. The theme-based learning stresses information integration, as opposed to teaching students discrete, unrelated pieces of knowledge.

Mission-based learning intends to help students develop a healthy attitude while facing stress and to foster their ability of accomplishing tasks at risk of failing. Today, schools evaluate students by

\footnotetext{
2 The use of the name "complex problem learning" is to address the complexity of the content to learn, because there is no decomposition, when compared to that of structural knowledge learning.
} 
how well they learn, but not by how well they achieve tasks. However, in society, one's school mark may not correlate with one's achievement. It is not surprising to find in alumni gatherings, that an old classmate who did poorly in school is very successful in his career. Commitment, persistence, and willingness to take risks are perhaps more important than learning ability to succeed in one's career. In a person's life, it is inevitable that s/he will face difficulties. Students have to learn in schools how to turn obstacles into opportunities (Stoltz \& Pulatie, 1997). Thus, the most critical characteristic of mission-based learning is that students have a good chance to fail in the activities. One way to do it is to impose constraints on the activities. For example, the teacher may ask the students to accomplish a task in limited time. After the task, the students should reflect why they succeeded or failed and what they have learnt.

The fourth space is creative problem solving (Parnes, 1992). There are some well-studied methods to help a person to be creative. For example, it is assumed that creative process involves idea generation, evaluation, and implementation, and there are methods to help a person at each step of the creative process. For instance, brainstorming can be used to help generating ideas. These methods, again, can be adopted in network learning environment. The following example uses the elections held in EduCities to illustrate how creative problem solving is implemented in EduCities (detailed information of EduCities will be presented in the next section). Except for system maintenance, which is under the control of a few system engineers, the users of EduCities are in charged of running EduCities. Like a real city, EduCities has a government, and any user can run for any government office. If a user is elected, s/he will be the major or the commissioner of the police department of EduCities, depending on the position $\mathrm{s} /$ he is running for. However, to be elected, a candidate has to generate ideas concerning how s/he will run the office and to make these ideas appeal to the other users. Thus, the user has to justify and to evaluate her/his ideas so that the other users will vote for her/ him. Of course, once elected, s/he has to execute what s/he proposed in the campaign.

\subsection{Community-based learning}

Reacting to the emergence of network societies, community-based learning is proposed. The basic assumption of community-based learning is that a well-behaved citizen of the network society will also behave in the real world society. This is quite possible because more and more, the network society will intermix with the real world society. Another related issue is that the average age of network users is getting younger and school kids are spending more and more time on the network; inappropriate contents for youngsters available on the network becomes a concern.

A Website, called EduCities, is a task force just initiated by researchers from several universities in Taiwan. The structure and operation of EduCities adopt the structure and operation of a real city for cultivating a learner-oriented learning society on the network. Citizens in this cyber city can be students, teachers, parents, and anyone who is willing to participate and contribute. As in a city of the real world, a lot of events will be held in EduCities to encourage the citizens to participate. There are various "bureaus" in the government of EduCities, which will provide plenty of positions such as police, judge, legislative, peer tutor, and so on, for the citizens to take up. Of course, there are privileges and obligations associated with these positions. Thus, EduCities is an "achieving society", where all the citizens will be able to make a contribution and be honored for their efforts.

Because there will be many homepages in EduCities for a visitor to choose, we are establishing "journals" for teachers and students. Every subject taught in school will have a journal that 
publishes the homepages designed by the citizens of EduCities. The reviewing process of a submitted homepage will resemble that of the academic journals. The most active teachers, and perhaps students, will serve on the editorial boards of these journals.

Constructing an educational network society is rather different from a general purpose network society, such as GeoCities. Not only the purpose and the design of activities are different, but also the way to organize participants and the system architecture. Most websites that adopt the city metaphor organize people who are already users on the network. EduCities, on the contrary, serves as an interface for organizing people in the existing organizations, such as schools, universities, government, non-profit organizations, to form a bigger organization. Not all of these people have already been network users, but through promotions, a lot of them will become EduCities citizens. For example, EduCities may offer seminars and workshops for teachers, and encourage them to connect their classrooms through EduCities, and to teach collaboratively. Indeed, the network is not only a medium for communication or information spreading, but also a medium for people with common interests to get together.

EduCities will rapidly evolve, much faster than the real world society had been because the network can reach many more people and the organizations in EduCities are virtual reality which can be formed overnight. Because many sectors of the Taiwanese society (e.g. the ministry of education, the education bureaus of a number counties, many universities, high schools, and elementary schools, and news medias) were involved in the development of EduCities, the city will be a perfect place for people to discuss, and be informed, how education will change in the network age. The development of EduCities can also be viewed as model as to how different social sectors can/should work together to improve education.

\section{Comparison of the four spaces}

The learning models of the four spaces can be further differentiated, and then be understood, from the following perspectives.

\subsection{Locations and times}

\subsubsection{Learner locations}

Despite the change of educational environment, the classroom will still be the most important place for learning; however, compared with the present situation, a larger portion of learning will take place outside of schools. Structural knowledge learning is usually done in the classroom, and partly at home. Complex-problem learning, however, could take place at various locations, such as school, home, or other appropriate sites. Learners who participate in community-based learning do so primarily at home. A student who is a network policeman of EduCities, for example, may be on-duty while at home.

\subsubsection{In class vs. after class}

An in class activity takes place during a normal class period in school, whereas an after class activity takes place outside of school. Most future classroom learning will take place in class. 
Structural knowledge learning and complex problem learning can be either in or after class. For instance, one type of structural knowledge learning, social scaffolding, can be carried either in or after class. The majority of community-based learning activities occur after class.

\subsubsection{Duration}

Future classroom learning normally lasts a school term. In structural knowledge learning, a student may spend from 30 min to several hours to learn a unit in a target-based learning activity; as for subject-based learning, it may take the student a month or a term depending on the complexity of the assigned subject. Often, a task in complex problem learning sustains for a school term, however a creative problem solving activity, which adopts some formats of brainstorming and group work, the duration may vary from hours to months. Community-based learning is a roleplaying activity, and may take only a few hours if the participants participate in a game, or continue for years if the participants assume a position in the government of the network society (Table 1).

\subsection{Participants}

\subsubsection{Teacher-centered vs. student-centered}

In the future, a shift of learning paradigm from the traditional teacher-centered activities to student-centered activities will occur. In future classroom learning, activities can be either teachercentered or student-centered. The activities of target-based learning are primarily student-initiative endeavors and hence target-based learning is student-centered. Although teachers play an active role in subject-based learning activities as coordinators, it can still be arranged so that the students are the center of the activities. The problems to be solved in complex problem learning or the roles taken in community-based learning are chosen by the students, and thus, the students should have strong motivation to participate in, and even a sense of attachment to, the learning activities. That is, a student will take an active role in the entire process of learning, from problem selection to problem solving planning, and to the execution of the plan. Activities, therefore, in complex problem learning and community-based learning are student-centered, with the teachers acting as facilitators.

Table 1

Comparison of locations and times

\begin{tabular}{|c|c|c|c|c|c|}
\hline \multirow[t]{2}{*}{$\begin{array}{l}\text { Model } \\
\text { properties }\end{array}$} & \multirow{2}{*}{$\begin{array}{l}\text { Future } \\
\text { classroom } \\
\text { learning }\end{array}$} & \multicolumn{2}{|c|}{$\begin{array}{l}\text { Structural knowledge } \\
\text { learning }\end{array}$} & $\begin{array}{l}\text { Complex problem } \\
\text { learning }\end{array}$ & \multirow{2}{*}{$\begin{array}{l}\text { Community } \\
\text { based } \\
\text { learning }\end{array}$} \\
\hline & & $\begin{array}{l}\text { Target } \\
\text { based } \\
\text { learning }\end{array}$ & $\begin{array}{l}\text { Subject } \\
\text { based } \\
\text { learning }\end{array}$ & $\begin{array}{l}\text { Theme Inquiry Mission Creative } \\
\text { based based based problem } \\
\text { learning learning learning solving }\end{array}$ & \\
\hline $\begin{array}{l}\text { Learner } \\
\text { locations }\end{array}$ & $\begin{array}{l}\text { School/outside } \\
\text { school }\end{array}$ & \multicolumn{2}{|c|}{ School/home } & School/home/outside school & Home/school \\
\hline In/after class & In & \multicolumn{2}{|c|}{ In/after } & In/after & After \\
\hline Duration & School term & A month & 30 min-hours & Hours-months & Hours-years \\
\hline
\end{tabular}




\subsubsection{Peers sources}

In the future classroom learning, learning peers are mainly from the same classroom except that in learning activities where inter-class, inter-school, and/or inter-university collaborations are required. In structural knowledge learning and complex problem learning, learning peers will be classmates in an in-class activity, whereas in an out-class activity, they can be chosen from any student involved in the network. In community-based learning, there will be a good chance a student working with a group of people from different social sectors and with different ages.

\subsubsection{Number of synchronous interacting participants}

Depending on whether it is a small group learning activity or a connected classroom activity, the number of participants in future classroom learning may vary from a few people to a group of 20 or 30 people, or even up to hundreds of people. In structural knowledge learning, typically there will be fewer participates in a target-based learning activity than that of a subject-based learning activity. For the complex problem learning, small group discussion is usually involved in the learning process, and thus only several people are involved. However, for theme-based learning, the size of the learning group can be larger because the learning group is formed on the network and anyone who is interesting in the theme can join the group. Finally, in communitybased learning, most of the information and discussion are presented in bulletin board systems, and thus the number of participants may vary from board to board and from time to time (Table 2).

\subsection{Interaction types}

\subsubsection{Collaboration}

In all the models, collaboration between students is required. In particular, in complex problem learning, not only the students need to collaborate with each other, but they also need to work with the others persistently.

Table 2

Comparison of participants

\begin{tabular}{|c|c|c|c|c|c|c|c|c|}
\hline \multirow[t]{2}{*}{$\begin{array}{l}\text { Models } \\
\text { properties }\end{array}$} & \multirow{2}{*}{$\begin{array}{l}\text { Future } \\
\text { classroom } \\
\text { learning }\end{array}$} & \multicolumn{2}{|c|}{$\begin{array}{l}\text { Structural knowledge } \\
\text { learning }\end{array}$} & \multicolumn{4}{|c|}{$\begin{array}{l}\text { Complex problem } \\
\text { learning }\end{array}$} & \multirow{2}{*}{$\begin{array}{l}\text { Community } \\
\text { based } \\
\text { learning }\end{array}$} \\
\hline & & $\begin{array}{l}\text { Target } \\
\text { based } \\
\text { learning }\end{array}$ & $\begin{array}{l}\text { Subject } \\
\text { based } \\
\text { learning }\end{array}$ & $\begin{array}{l}\text { Theme } \\
\text { based } \\
\text { learning }\end{array}$ & $\begin{array}{l}\text { Inquiry } \\
\text { based } \\
\text { learning }\end{array}$ & $\begin{array}{l}\text { Mission } \\
\text { based } \\
\text { learning }\end{array}$ & $\begin{array}{l}\text { Creative } \\
\text { problem } \\
\text { solving }\end{array}$ & \\
\hline $\begin{array}{l}\text { Teacher/student } \\
\text { centered }\end{array}$ & Vary & Student & Vary & \multicolumn{4}{|c|}{ Student } & Student \\
\hline Pee sources & $\begin{array}{l}\text { Class/variable } \\
\text { sources }\end{array}$ & $\begin{array}{l}\text { Class/variable } \\
\text { sources }\end{array}$ & Class & \multicolumn{4}{|c|}{ Class/variable sources } & $\begin{array}{l}\text { Variable } \\
\text { sources }\end{array}$ \\
\hline $\begin{array}{c}\text { Synchronous } \\
\text { interacting } \\
\text { numbers }\end{array}$ & $\begin{array}{l}\text { Several } \\
\text { or tens }\end{array}$ & $\begin{array}{l}\text { Two or } \\
\text { several }\end{array}$ & $\begin{array}{l}\text { Several } \\
\text { or tens }\end{array}$ & $\begin{array}{l}\text { Several } \\
\text { or tens }\end{array}$ & & Several & & $\begin{array}{l}\text { Variable } \\
\text { numbers }\end{array}$ \\
\hline
\end{tabular}




\subsubsection{Peer tutoring or mentoring}

Generally, this perspective is not applicable in the future classroom learning, however, peer tutoring or mentoring is much needed in the other types of learning models, especially community-based learning.

\subsubsection{Team competition}

Inter-group competition is a strategy traditionally used to enhance in-group identification and collaboration. Thus, team competition is applicable to all of the learning models. However, it should not be overly applied in theme-based and inquiry-based learning, because in these learning models, participants usually have their own learning goals. Furthermore, these models emphasize team collaboration and the collaboration process is not only a means to achieve the perspective learning goals but an opportunity to foster social skills (Table 3 ).

\subsection{Media}

\subsubsection{Interactive media}

Unlike books or videos, in face-to-face situations, information presenters and receivers can exchange ideas, and thus face-to-face communication is an interactive media. Although in future classroom learning, interaction is primarily face-to-face, it will be complemented with "networking", where the learners correspond with each other through the network. Similar to face-to-face communication, the network is also an interactive media, and thus is appropriate for all the learning models, especially community-based learning where face-to-face communication, although not impossible, rarely takes place.

\subsubsection{Network types}

Intranet, Internet, and short distance wireless communication network will all be used in future classroom learning, as well as in structural knowledge and complex problem learning. Some outdoor learning activities, however, may require long distance wireless communication network or a satellite. The Internet will be used in most activities associated with communitybased learning.

Table 3

Comparison of interaction types

\begin{tabular}{|c|c|c|c|c|c|c|c|c|}
\hline \multirow[t]{2}{*}{$\begin{array}{l}\text { Models } \\
\text { properties }\end{array}$} & \multirow{2}{*}{$\begin{array}{l}\text { Future } \\
\text { classroom } \\
\text { learning }\end{array}$} & \multicolumn{2}{|c|}{$\begin{array}{l}\text { Structural knowledge } \\
\text { learning }\end{array}$} & \multicolumn{4}{|c|}{$\begin{array}{l}\text { Complex problem } \\
\text { learning }\end{array}$} & \multirow{2}{*}{$\begin{array}{l}\text { Community } \\
\text { based } \\
\text { learning }\end{array}$} \\
\hline & & $\begin{array}{l}\text { Target } \\
\text { based } \\
\text { learning }\end{array}$ & $\begin{array}{l}\text { Subject } \\
\text { based } \\
\text { learning }\end{array}$ & $\begin{array}{l}\text { Theme } \\
\text { based } \\
\text { learning }\end{array}$ & $\begin{array}{l}\text { Inquiry } \\
\text { based } \\
\text { learning }\end{array}$ & $\begin{array}{l}\text { Mission } \\
\text { based } \\
\text { learning }\end{array}$ & $\begin{array}{l}\text { Creative } \\
\text { problem } \\
\text { solving }\end{array}$ & \\
\hline Collaboration & Applicable & \multicolumn{2}{|c|}{ Applicable } & \multicolumn{4}{|c|}{ Persistent teamwork } & Applicable \\
\hline $\begin{array}{l}\text { Peer tutoring/ } \\
\text { mentoring }\end{array}$ & $\begin{array}{l}\text { Usually not } \\
\text { applicable }\end{array}$ & \multicolumn{2}{|c|}{ Needed } & \multicolumn{4}{|c|}{ Applicable (with teacher monitoring) } & $\begin{array}{l}\text { Strongly } \\
\text { needed }\end{array}$ \\
\hline $\begin{array}{l}\text { Team } \\
\text { competition }\end{array}$ & Applicable & \multicolumn{2}{|c|}{ Applicable } & \multicolumn{2}{|c|}{ Not so applicable } & \multicolumn{2}{|c|}{ Applicable } & Applicable \\
\hline
\end{tabular}




\subsubsection{Bandwidth}

The bandwidth required for a learning model depends on the type of media used. Usually, larger bandwidth is required for future classroom learning because face-to-face communication is considered as one of board band media. However, for community-based learning, it is less demanding because the learners are usually communicating with each other through bulletin board systems (Table 4).

\subsection{Knowledge and knowledge to learn}

\subsubsection{Knowledge types}

In future classroom and structural knowledge learning, a student may learn all types of knowledge (e.g. learn how to learn) and skills (e.g. social skills), although these learning models concern primarily how to construct a learning environment so that students can learn the fundamental academic knowledge such as reading, writing, and arithmetic effectively. In complex problem learning, students learn not only the knowledge but other knowledge as well. For example, in a theme-based learning activity, the students will have a chance to apply the acquired knowledge in real world, and in an inquiry-based learning activity, they will do what a scientist does in conducting research, and thus learn not only the process of conducting a specific type of research but also the general knowledge of information integration and analysis. In a mission-based learning activity, students will learn to accomplish a task under stress, and in a creative problem solving activity, they will learn how to generate and to apply imaginative solutions to complex problems. Finally, community-based learning nurtures students' social skills and sense of responsibility for themselves.

\subsubsection{Knowledge structure}

As the name implies, in structural knowledge learning, the to-be- learnt knowledge is well organized, and is readily accessible. However, in the other learning models, especially complex

Table 4

Comparison of media

\begin{tabular}{|c|c|c|c|c|c|c|c|c|}
\hline \multirow[t]{2}{*}{$\begin{array}{l}\text { Models } \\
\text { properties }\end{array}$} & \multirow{2}{*}{$\begin{array}{l}\text { Future } \\
\text { classroom } \\
\text { learning }\end{array}$} & \multicolumn{2}{|c|}{$\begin{array}{l}\text { Structural knowledge } \\
\text { learning }\end{array}$} & \multicolumn{4}{|c|}{$\begin{array}{l}\text { Complex problem } \\
\text { learning }\end{array}$} & \multirow{2}{*}{$\begin{array}{l}\text { Community } \\
\text { building \& } \\
\text { community } \\
\text { based } \\
\text { learning }\end{array}$} \\
\hline & & $\begin{array}{l}\text { Subject } \\
\text { based } \\
\text { learning }\end{array}$ & $\begin{array}{l}\text { Target } \\
\text { based } \\
\text { learning }\end{array}$ & $\begin{array}{l}\text { Theme } \\
\text { based } \\
\text { learning }\end{array}$ & $\begin{array}{l}\text { Inquiry } \\
\text { based } \\
\text { learning }\end{array}$ & $\begin{array}{l}\text { Mission } \\
\text { based } \\
\text { learning }\end{array}$ & $\begin{array}{l}\text { Creative } \\
\text { problem } \\
\text { solving }\end{array}$ & \\
\hline $\begin{array}{l}\text { Interaction } \\
\text { media }\end{array}$ & $\begin{array}{l}\text { Face to face/ } \\
\text { network }\end{array}$ & \multicolumn{2}{|c|}{$\begin{array}{l}\text { Network } \\
\text { /face to face }\end{array}$} & \multicolumn{4}{|c|}{ Face to face/network } & Network \\
\hline $\begin{array}{l}\text { Network } \\
\text { types }\end{array}$ & $\begin{array}{l}\text { Intranet/ } \\
\text { Internet/ } \\
\text { wireless/ } \\
\text { satellite }\end{array}$ & \multicolumn{2}{|c|}{$\begin{array}{l}\text { Internet/ } \\
\text { Intranet/ } \\
\text { wireless }\end{array}$} & \multicolumn{4}{|c|}{ Internet/wireless computers/satellite } & Internet \\
\hline Bandwidth & Wide & \multicolumn{2}{|c|}{ Variable bandwidth } & \multicolumn{4}{|c|}{ Variable bandwidth } & Narrow \\
\hline
\end{tabular}


problem learning and community-based learning, unorganized information may need to be searched from the network in order to solve a problem or perform a duty.

\subsubsection{Knowledge integration vs. knowledge segmentation}

The four spaces of learning models have different emphases, and thus, the information or knowledge is arranged differently in different models. For example, in complex problem learning and community-based learning, various types of information and knowledge are involved, and the students are encouraged to integrate the information and knowledge creatively. However, in a structural knowledge learning activity, it usually involves specific knowledge, and the knowledge is usually well organized or segmented so that the students can learn the knowledge effectively.

\subsubsection{Knowledge aqcquisition vs. knowledge application}

Both knowledge acquisition and application will be emphasized in future classroom learning. Knowledge acquisition is especially emphasized in structural knowledge learning, conversely in complex-problem learning, knowledge application is typically the major concern. Both knowledge acquisition and application are involved in community-based learning since the students participate in network social activities, and they will reflect upon their network social experience and thus acquire new knowledge, and later on, apply the acquired knowledge in their social activities (Table 5).

\section{Model multiplicity of learning activity}

A learning activity may occur in more than one space. Let us consider an activity model in future classroom learning. New computational devices used in classrooms usually generate new

Table 5

Comparison of knowledge to learn

\begin{tabular}{|c|c|c|c|c|c|c|c|c|}
\hline \multirow[t]{2}{*}{$\begin{array}{l}\text { Model } \\
\text { properties }\end{array}$} & \multirow{2}{*}{$\begin{array}{l}\text { Future } \\
\text { classroom } \\
\text { learning }\end{array}$} & \multicolumn{2}{|c|}{$\begin{array}{l}\text { Structural knowledge } \\
\text { learning }\end{array}$} & \multicolumn{4}{|c|}{ Complex problem learning } & \multirow{2}{*}{$\begin{array}{l}\text { Community } \\
\text { based } \\
\text { learning }\end{array}$} \\
\hline & & $\begin{array}{l}\text { Subject } \\
\text { based } \\
\text { learning }\end{array}$ & $\begin{array}{l}\text { Target } \\
\text { based } \\
\text { learning }\end{array}$ & $\begin{array}{l}\text { Theme } \\
\text { based } \\
\text { learning }\end{array}$ & $\begin{array}{l}\text { Inquiry } \\
\text { based } \\
\text { learning }\end{array}$ & $\begin{array}{l}\text { Mission } \\
\text { based } \\
\text { learning }\end{array}$ & $\begin{array}{l}\text { Creative } \\
\text { problem } \\
\text { solving }\end{array}$ & \\
\hline $\begin{array}{l}\text { Knowledge } \\
\text { types }\end{array}$ & All & Academ & knowledge & $\begin{array}{l}\text { Real world } \\
\text { knowledge }\end{array}$ & $\begin{array}{l}\text { Scientific } \\
\text { inquiry }\end{array}$ & $\begin{array}{l}\text { Learning } \\
\text { task } \\
\text { execution }\end{array}$ & $\begin{array}{l}\text { Creative } \\
\text { thinking } \\
\text { skills }\end{array}$ & Social skills \\
\hline $\begin{array}{l}\text { Knowledge } \\
\text { structure }\end{array}$ & $\begin{array}{l}\text { Variable } \\
\text { structure }\end{array}$ & \multicolumn{2}{|c|}{ Well structured } & \multicolumn{4}{|c|}{ Unstructured complex problems } & Unstructured \\
\hline $\begin{array}{l}\text { Knowledge } \\
\text { integration/ } \\
\text { segmentation }\end{array}$ & $\begin{array}{l}\text { Variable } \\
\text { integration }\end{array}$ & \multicolumn{2}{|c|}{ Segmentation } & \multicolumn{4}{|c|}{ Integration } & Integration \\
\hline $\begin{array}{l}\text { Knowledge } \\
\text { acquisition/ } \\
\text { application }\end{array}$ & $\begin{array}{l}\text { Application/ } \\
\text { acquisition }\end{array}$ & \multicolumn{2}{|c|}{ Acquisition } & \multicolumn{4}{|c|}{ Application } & Application \\
\hline
\end{tabular}


learning models. For example, if every student in the classroom has a schoolbag computer, then the students may by divided into small groups to conduct research concerning the water quality at the region they are living (an inquiry-based learning activity, a subspace of complex problem learning). The students use the Internet to search for information, and then use the software stored in the schoolbag computers to analyze the data collected. The research process may continue after school, and at home, the students may visit the homepage of an environmental protection group on the Internet to discuss their research or to seek help. Thus, the activity has become a model in community-based learning. The next day, in the class, each group dispatches a representative to present their research results to the whole class. Finally, to conclude the activity, the groups may conduct self-evaluation or mutual-evaluation via some sort of remote voting using their schoolbag computers.

Therefore, despite our attempt to distinguish learning models into four spaces, a learning activity may combine the characteristics of more than one learning space. Nevertheless, the decomposition of the possible network learning models into four spaces enables us to conceptualize, as well as to investigate and to anticipate, the direction that network learning is heading in the future.

\section{EduCities: integrative platform of learning models}

EduCities, which serves as a portal site for the learners, was built on the Web. Currently, it is the entry point for all the systems developed by different laboratories in Taiwan, supporting different learning models. In the future, while similar systems are built in other countries, the users can access the learning activities in the other "EduCities".

In EduCities, a learner can find not only learning activities to participate and learning materials to read, but also learning companies, tutors and tutees if s/he wishes to contribute her/his learning experience. Moreover, with the learners' consent, a log which records the learners' learning processes with their personal identifications removed will be kept in EduCities. These records should serve at least two functions. First, the log provides valuable data for the researchers to investigate the effects of the four spaces of learning models. Secondly, the records contained in the log provide useful references for the students. For example, when a student encounters problems while participating in a learning activity, s/he can search the log for other students' records, who had similar problems. The student can take the other students' successful, or failure, experiences into consideration while solving the problem. The next section will discuss further the usefulness of the learning log.

Almost all websites that adopt the city metaphor are centralized and single-layered. EduCities, on the contrary, is a distributed system composed of several layers. EduCities is in fact a series of associated layered systems. EduCities which is the headquarter of the entire system is the first layer. EduTowns which is the second layer comprises of the servers of the participating schools. EduRooms which is the third layer comprises of the servers of the "classrooms" of the participating schools. EduCitizens which is the fourth layer comprises of personalized systems for individual citizens who can be students, teachers or any one who is interesting in learning or teaching.

EduCities has been running for about a year, and much experience concerning the operation of the system has been gained during this period. When we understand EduCities better, we shall 
invite and help institutes of other countries to develop their EduCities to form the International EduCities Consortia. Citizens across EduCities can participate various learning activities on the network. Face-to-face meetings during vacations can be arranged for the citizens as well as the mayors of sister EduCities to exchange their ideas and experiences. EduCities is therefore a vehicle for promoting global network education, through which, we can further excel research results and share learning resources internationally (Fig. 8).

\section{6. 'Individualized' network learning}

Individualization is not limited to standalone computers, like those traditional intelligent tutoring systems. In the network environment, if the system is 'knowledgeable' and intelligent enough, it can take into account the special needs of individual learners. In principle, every keystroke or movement can be recorded by the computer and collected in the servers through the network. Potentially there will be a huge database of learning profiles possibly stored in distributed locations. This is a huge database because it collects the learning histories of a large group of people. This indicates that the system can be an "expert" of learning behaviors, provided that the system is programmed to be able to exploit this database intelligently and appropriately. For example, if a student has to choose from two learning activities, A and B, the system can search through the database for all the students who had the same learning path as the targeting student. If the system finds that learning activities B produced better results than A for most of the other students, it will recommend the targeting student to take B. To push this concept further, everyone in the future can have an individualized curriculum based on one's own interest, background, and potential.

How to utilize the huge database of the learning profiles poses a challenge to future research. In the context of network learning, besides helping teachers to evaluate students, the system can also help to find an appropriate learning partner on the network for a particular student to work together in a network learning activity (Ikeda, Go, \& Mizoguchi, 1997; Fig. 9).

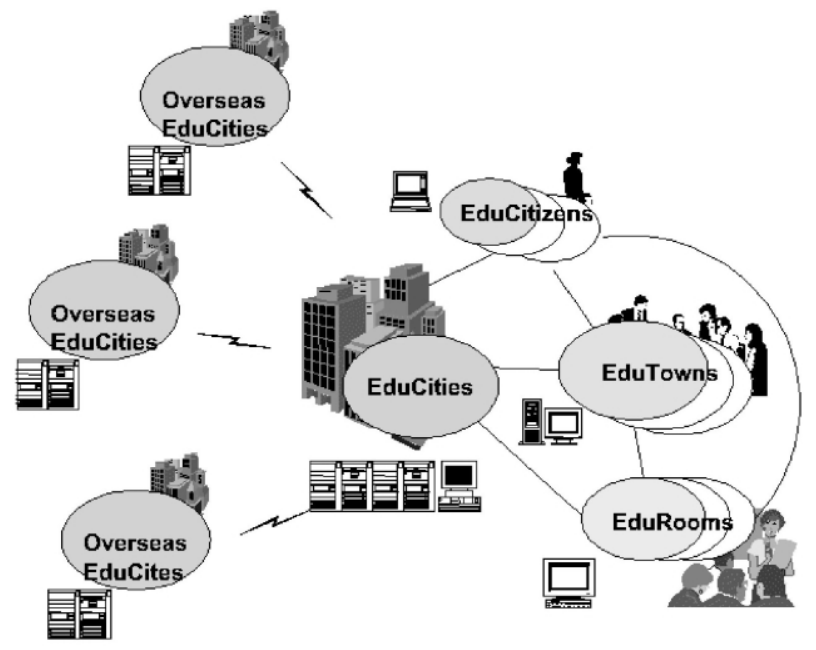

Fig. 8. Distributed and layered systems. 
Educational agents are simulated agents with animated or lifelike personas, that can interact more naturally with learners and make the learning context more realistic. The persona can express attitudes and moods, demonstrate the skills being learned, and use nonverbal cues to help the learner's focus their attention. Personified agents can assume a variety of possible roles in computer-based learning environments, including tutors, learning companions, critics, teammates, guides, etc.

A dream of educational agent design is that every student in the future has a set of lifelong learning companions. For a youngster, s/he may choose a set of "animal" companions, and in her/his school years, s/he will be like a leading character in a Disney cartoon movie always surrounded by the companions. Every animal companion can assume a different role. For example, a dalmatian is a collaborator. Mushu dragon is a peer tutor. Monkey king is a trouble maker, who challenges the student from time to time. Tamagochi (a once popular electronic chick that can be incubated by kids) can be taught by the student to play against the other Tamagochies raised by other students in some network learning games. In other words, we can 'disneyficate' the learning environment (Fig. 10; Chan, 1996; Chang, Wang, Hsu, \& Chan, 2000; Fig. 10)

\section{Summary}

Despite the seemingly complex system to be developed, there is a simple and intuitive layered architecture that can be regarded as a summary of network learning development. The bottom layer is hardware and network infrastructure. The second layer is a set of basic software tools, for

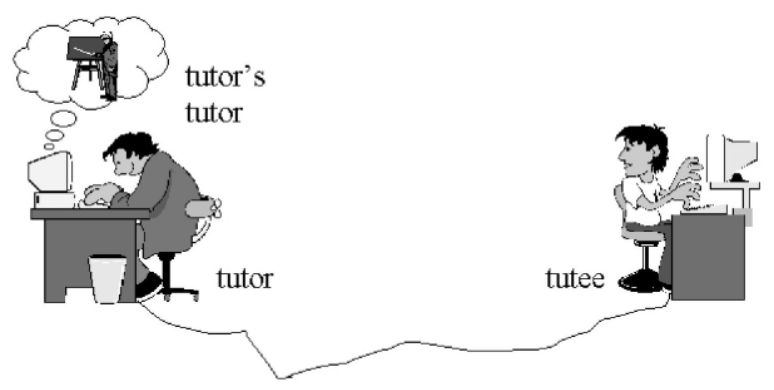

Fig. 9. Simulated tutor's tutor in reciprocal tutoring.

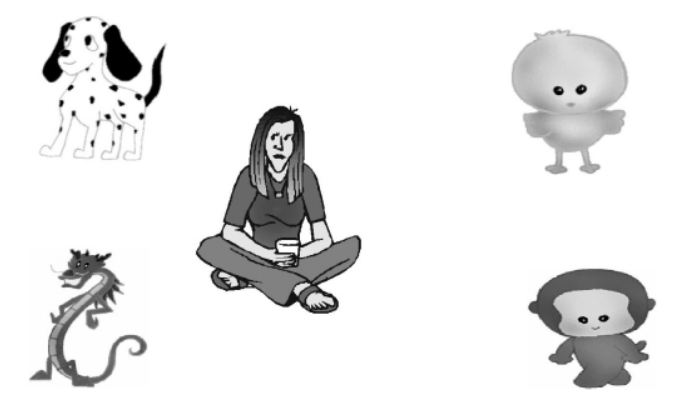

Fig. 10. My animal companions - 'Disneyficating the learner'. 


\begin{tabular}{|c|}
\hline evaluation \\
\hline \hline intelligent educational agents \\
\hline \hline learning profiles \\
\hline \hline learning activity models \\
\hline \hline content \\
\hline \hline basic tools \\
\hline network \& hardware infrastructure \\
\hline
\end{tabular}

Fig. 11. Layered architecture of network learning.

example, browsers, and content materials, for example, school mathematic textbooks. With these basic utilities, learning activities on the network can be designed so that learners can use the software tools to interact with each other and to access the content materials. Further, during learning, the learners are expected to produce new learning materials and activities, and perhaps software tools. The architecture depicted so far is similar to most of the current network learning systems. That is, on top of the hardware and content materials, there are learning activities. However, in our system, there is another layer on top of the learning activities, that is, the learners' learning profiles. As discussed above, the learning profiles allow us to investigate the methods to evaluate students' learning performance, and to design educational agents. Most of all, the learning profiles provide information concerning the effectiveness of the whole system, and data for us to theorize network learning behavior (Fig. 11).

In this paper, we have described four spaces of network learning models. We believe that investigation of these learning models will shed light on the design and the effects of network learning environment. We conceived these spaces based on issues that will affect our society in the near future, therefore the four spaces provide directions concerning future research and development of information and communication technologies supporting or/and leading the educational reform in the real world.

\section{Acknowledgements}

The authors would like to thank all the members involved in the Learning Technology project, as well as the National Science Council for their long-term support in the past. The Learning Technology project is supported by a grant from the Ministry of Education, No. 89-HFA07-1-4. The authors also thank Prof. R. Lewis, C.C. Hsieh, C.H. Liu and J. Krajcik, who are only a few of the people who gave us valuable advice on the project 


\section{References}

Barnard, Y., \& Sandberg, J. (1993). Open learning environment: what support should they offer? Proceedings of International Conference on Computers in Education, Taipei, Taiwan, 156-161.

Bell, P., Davis, E., \& Linn, M. (1995). The knowledge integration environment: theory and design. Proceedings of the Computer Supported Collaborative Learning Conference, Bloomington, Indiana, 14-21.

Brown, J. S. (1998). Leveraging the web for creating learning ecologies. Invited Talk, The Sixth International Conference on Computers in Education, Beijing, http://www.apc.src.ncu.edu.tw/

Chan, K. F. (1999). How to raise your $A Q, C Q, E Q$ and $I Q$. Hong Kong Ming Pao Publishing (in Chinese).

Chan, T. W. (1996). Learning companion systems, social learning systems, and global social learning clubs. Invited talk. Proceedings of World Conference on Artificial Intelligence in Education, Washington, DC, USA, Journal of Artificial Intelligence in Education, Vol. 7, No. 2, 125-159.

Chan, T. W., Chung, R. G., Ho, R. G., \& Lin, G. L. (1992). Distributed learning companion system: west revisited, Proceedings of The Second International Conference on Intelligent Tutoring Systems, Canada, 643-650.

Chang, L. J., Wang, J. C., Hsu, B. Y., \& Chan, T. W. (2000). Four applications of student modeling - my animal companions. Proceedings of The Third Global Chinese Conference on Computers in Education, Macau, 366-370.

Education and Manpower Bureau (1998). Information technology for learning in a New Era (Five-Year Strategy 1998/ 1999 to 2002/2003). Hong Kong.

Education and Manpower Bureau (2000). A proposal for educational reform in Hong Kong. Hong Kong.

Gagne, R. (1985). The conditions of learning (4th ed.). New York: Holt, Rinehart \& Winston.

Hoffman, J. L., Kupperman, J., \& Wallace, R. (1997). On-line learning materials for the science classroom: design methodology and implementation. In E. Soloway (symposium chair), Using on-line digital resources to support sustained inquiry learning in K12 science. Symposium conducted at the meeting of the American Educational Research Association, Chicago, IL.

Ikeda, M., Go, S., \& Mizoguchi, R. (1997). Opportunity group formation - a theory for intelligent support in collaborative learning. Proceedings of the Eighth Artificial Intelligence in Education, Japan, 167-174.

Krajcik, J. S. (2000). Advantages and challenges of using the world wide web to fosters sustained science inquiry in middle and high classrooms, invited talk. Proceedings of Symposium on the Effects of the Internet on Education, Taipei, Taiwan, 23-40.

Ministry of Education (1997). Master plan for IT in education. Singapore.

Ministry of Education (1998). Action plan for educational reform. Taiwan. http://www.edu.tw/minister/action87/ action87.htm.

Parnes, S. J. (1992). Sourcebook of creative problem solving. Buffalo, NY: Creative Education Foundation.

Stoltz, P. G., \& Pulatie, D. (1997). Adversity quotient:turning obstacles into opportunities, John Wiley \& Sons.

Wallace, P. (1999). The psychology of the Internet. Cambridge, UK: Cambridge University Press.

Whitaker, P. (1995). Managing to learn. London: Cassell. 